\title{
Challenges and opportunities for development of the Vietnam mineral processing in the XXI century
}

\author{
Luan Van Pham* \\ Hanoi University of Mining and Geology, Hanoi, Vietnam
}

ARTICLE INFO

Article history:

Received 18 ${ }^{\text {th }}$ Feb. 2021

Revised $19^{\text {th }}$ May 2021

Accepted 19th June 2021

Keywords:

Mineral processing plants,

Mineral processing,

Minerals,

Recycling,

Waste.
ABSTRACT

Mineral mining and processing Industry of Vietnam is facing a number of huge challenges at present, but there are also great opportunities for its growth in the future. Mineral processing plants need to make breakthrough improvements in the process designing, technology and equipment utilisation in order to meet requirements of the new era. These challenges force our miners and mineral processing operators to constantly make efforts in researches and to bring best solutions to improve plant operations to ensure the requirements of safety, market demands, product quality, sustainable development and environmental friendliness. Specifically, the issues that need to be addressed urgently are capacity and quality of the workforce, tailings treatment, fine particle processing, ores of low washability, recovery rate increase and maximisation of recoverable valuable minerals, environmental issues and workplace safety monitoring and control, maximasation of production efficiency and reduction of operating costs. This report presents the current key challenges of the mining and mineral processing industry in order to help professionals and policy makers in the field of mineral mining and processing to bring rational directions for action initiate appropriate studies and improve management methods; to help mineral processing plants in improving the production efficiency and recovery of valuable minerals; to reduce operating costs and to become environmentally friendly and to develop sustainably.

${ }^{*}$ Corresponding author

E - mail: phamvanluan@humg.edu.vn

DOI: $10.46326 / J M E S .2021 .62(3 b) .01$ 


\title{
Tạp chí Khoa học Kỹ thuật Mỏ - Địa chất
}

Trang điện tử: http://tapchi.humg.edu.vn

\section{Những thách thức và cơ hội phát triển của ngành Tuyển khoáng Việt Nam trong thế kỷ XXI}

\author{
Phạm Văn Luận * \\ Truờng Đại học Mỏ - Địa chất, Hà Nội, Việt Nam
}

\section{THÔNG TIN BÀI BÁO TÓM TẮT}

Quá trình:

Nhận bài 18/02/2021

Sứa xong 19/5/2021

Chấp nhận đăng 19/6/2021

\section{Tù̀ khóa:}

Khoáng sản,

Nhà máy tuyển,

Rác thải,

Tái chế,

Tuyển khoáng.
Hiện nay, ngành công nghiệp tuyển và chế biến khoáng sản Việt Nam phải đối mặt với nhiều thách thức, nhưng cũng có co hội tốt để phát triển. Các nhà máy tuyển khoáng cần có nhũng cải tiến đột phá về thiêt kế, công nghệ và thiết bị, để đáp ứng được những yêu cầu trong thời đại mói. Những thách thức này, buộc các nhà hoạt động trong lĩnh vực tuyển và chế biến khoáng sản không ngùng nỗ lực nghiền cứu, đưa ra các giải pháp tối ưu cải thiện hoạt động của nhà máy nhằm đảm bảo các yêu cẩu về: an toàn, nhu cầu thị trường, chất lượng sản phẩm, phát triển bền vũng và thân thiện với môi trường. Cụ thể, một số vấn đề cấp bách cần phải giải quyết là: năng lực và chất lượng của lực lượng lao động, xử lý đuôi thải , vấn đề tuyển quặng xâm nhiễm min và khó tuyển, tăng thực thu và thu hồi tối đa các khoáng vật có ích, các vấn đề môi trường, giám sát và kiểm soát mức độ an toàn tại nơi làm việc, tối đa hiệu quả sản xuất và giảm chi phí vận hành. Báo cáo này trình bày và phân tích về nhũng thách thức chính mà ngành Tuyển khoáng Việt Nam đang phải đối mặt, nhằm giúp các chuyên gia và các nhà quản lý hoạt động trong lĩnh vực tuyển và chế biến khoáng sản đưa ra các phương hướng hành đông; khởi xướng các nghiên cứu thích hợp và cải tiến phương pháp quản lý, nhằm giúp các nhà máy tuyển nâng cao hiệu quả tuyển và thu hồi các chất có ích, giảm giá thành tuyển, thân thiện với môi trường và phát triển bền vững.

C 2021 Trường Đại học Mỏ - Địa chất. Tất cả các quyền được bảo đảm.

\section{Mở đầu}

Ngành Tuyển khoáng Việt Nam được bắt đầu hình thành và phát triển từ những năm 60 của thế kỷ trước, nhưng chỉ thực sự phát triển mạnh mẽ trong khoảng 25 năm gần đây. Trong giai đoạn

\section{*Tác giả liên hệ}

E-mail: phamvanluan@humg.edu.vn

DOI: 10.46326/JMES.2021.62(3b).01 này, ngành Tuyển khoáng Việt Nam đã có nhiều phát triển vượt bậc, minh chứng bằng việc đã có nhiều nhà máy tuyển mới sử dụng công nghệ tiệm cận so với thế giới được xây dựng; một số thành tựu công nghệ của nhân loại trong lĩnh vực tuyển và chế biến khoáng sản đã được tiếp thu như: các thiết bị được áp dụng những nguyên lý hoạt động mới, các hóa chất tuyển hiện đại và có chú trọng đến công tác bảo vệ môi trường. Điển hình là các nhà máy tuyển quặng đa kim Núi Pháo, nhà máy tuyển đồng Sin Quyền II,... 
Tuy nhiên, vẫn còn tồn tại nhiều nhà máy tuyển công suất nhỏ công nghệ lạc hậu, hiệu suất tuyển thấp, gây lãng phí tài nguyên và ô nhiễm môi trường ở Việt Nam. Hiệu quả thu hồi các thành phần có ích đi kèm trong quặng nguyên khai còn thấp, vấn đề xử lý đuôi thải và môi trường chưa được chú trọng. Mức độ tự động hóa còn hạn chế, năng suất lao động thấp,... Cá biệt, một vài doanh nghiệp khai khoáng ở Việt Nam hiện nay chỉ chú trọng thu lợi nhuận nhanh, không quan tâm đến khâu tuyển và chế biến để nâng cao giá trị và hiệu quả sử dụng tài nguyên khoáng sản, đồng thời cũng gây lãng phí tài nguyên do không tận thu được các khoáng vật khác đi kèm và gây ô nhiễm môi trường. Nhiều mỏ với quy mô khai thác nhỏ, mức độ cơ giới hóa thấp và công nghệ khai thác lạc hậu. Do vậy, chỉ lấy được những phần quặng giàu nhất, bỏ đi quặng trung bình và quặng nghèo. Đáng lo ngại hơn, việc khai thác theo dạng "ăn xổi" gây tổn thất nặng nề cho tài nguyên khoáng sản quốc gia và ảnh hưởng nghiêm trọng đến môi trường. Những điểm yếu trên cần được ngành Tuyển khoáng Việt Nam chú trọng cải tiến trong thời gian tới.

Trong những năm gần đây, các phế thải rắn công nghiệp phát sinh ra ngày càng lớn, bao gồm các loại: rác thải điện tử; rác thải xây dựng; tro và xỉ của các nhà máy nhiệt điện đốt than; bụi và xỉ của các nhà máy luyện gang thép; bùn đỏ của các nhà máy alumin; đuôi thải và xỉ của các nhà máy tuyển khoáng, luyện kim và chế biến khoáng sản,... Các nguồn phế thải rắn này hầu như chưa được kiểm soát và xử lý hiệu quả, gây ô nhiễm môi trường. Đòi hỏi việc kiểm soát và xử lý các phế thải rắn theo hướng thân thiện với môi trường là một thách thức lớn tại Việt Nam hiện nay.

Phát triển công nghệ tái chế và tái sử dụng phế thải rắn sinh ra trong quá trình sản xuất sẽ góp phần: tiết kiệm tài nguyên và năng lượng; giảm suy thoái môi trường; giảm chi phí xử lý lượng phế thải rắn ra môi trường; tăng nguồn cung cấp nguyên liệu khoáng sản cho các ngành công nghiệp. Có thể khẳng định: phát triển công nghiệp tái chế là nền tảng để phát triển bền vững ngành công nghiệp khai khoáng và chế biến khoáng sản. Đây là nhiệm vụ và là cơ hội để phát triển, nhưng cũng là thách thức không nhỏ cho các kỹ sư và ngành Tuyển khoáng Việt Nam trong thời gian tới.

\section{Những thách thức và cơ hội phát triển}

\subsection{Nguồn nhân lụ̂c}

Trong vài năm gần đây, ngành công nghiệp khai khoáng Việt Nam bắt đầu gặp nhiều khó khăn. Giá bán quặng tinh thấp, giá thành khai thác chế biến tăng, công nghệ lạc hậu và quản lý có phần yếu kém đã làm cho nhiều công ty khai khoáng làm ăn thua lỗ. Bởi vậy, các công ty hoạt động trong lĩnh vực khai khoáng và chế biến khoáng sản buộc phải cắt giảm chế độ tiền lương và các phúc lợi xã hội của người lao động, giảm biên chế, giảm số giờ làm việc, không tuyển lao động mới,... nhằm duy trì sản xuất, vô tình đã đẩy một lượng lớn lao động có tay nghề cao phải chuyển công tác hoặc nghỉ chế độ trước thời hạn,... Đồng thời, nhiều công ty không có nhu cầu tuyển lao động mới, nên số lượng sinh viên tốt nghiệp làm đúng ngành nghề giảm; môi trường làm việc nặng nhọc, vất vả nhưng thu nhập thấp đã làm cho ngành công nghiệp khai khoáng và chế biến khoáng sản không thu hút được thí sinh đăng ký học nghề cũng như học cao đẳng và đại học. Số lượng sinh viên đăng ký học ngành Tuyển khoáng tại Trường Đại học Mỏ - Địa chất trong vài năm gần đây giảm nghiêm trọng (Số liệu tuyển sinh, Khoa Mỏ) (Bảng 1).

Bảng 1. Sốlượng tuyển sinh của ngành Tuyển khoáng.

\begin{tabular}{|c|c|c|c|c|c|c|c|}
\hline Năm & 2014 & 2015 & 2016 & 2017 & 2018 & 2019 & 2020 \\
\hline $\begin{array}{c}\text { Số } \\
\text { lượng }\end{array}$ & 120 & 60 & 30 & 20 & 7 & 10 & 9 \\
\hline
\end{tabular}

Từ những phân tích trên có thể nhận thấy, ngành công nghiệp chế biến khoáng sản rất có khả năng sẽ phải đối mặt với tình trạng thiếu lao động tay nghề cao trong những năm tới. Đồng thời với thực trạng khai thác quặng ngày càng khó khăn, không tăng được sản lượng, giá thành khai thác tăng, nhiều lao động có kinh nghiệm và tay nghề cao ở thế hệ trước đã nghỉ hưu hoặc sắp bước vào tuổi nghỉ hưu,... Do đó, ngành Tuyển khoáng cần có phương án đào tạo thay thế để giữ lại những kinh nghiệm quý báu của các lao động có tay nghề cao trước khi họ rời khỏi lực lượng lao động. Cần đặc biệt chú trọng công tác đào tạo nhân viên có khả năng giám sát, điều khiển,... để nhà máy làm việc đúng quy trình kỹ thuật nhằm duy trì và nâng cao hiệu quả hoạt động của nhà máy. Việc đào tạo 
cần thực hiện càng sớm càng tốt, vì nếu thiếu kinh nghiệm, thiếu trình độ,... thì sẽ làm cho quá trình sản xuất đối diện với nguy cơ rủi ro và mất an toàn lao động ngày càng cao.

\subsection{Sức khỏe và an toàn lao động}

Trong những năm gần đây, các yêu cầu về chất lượng môi trường nơi làm việc của người lao động đã được các cơ quan Nhà nước ngày càng quan tâm. Vì mục đích bảo vệ sức khỏe và an toàn cho người lao động là ưu tiên hàng đầu, nên các yêu cầu này ngày càng khắt khe hơn. Để tránh vi phạm luật lao động, các nhà sản xuất cần phải đảm bảo điều kiện môi trường làm việc (tiếng ồn, ánh sáng, nồng độ bụi, khí thải,...) theo đúng quy định (nhiều khi rất khó đáp ứng) và trang bị đầy đủ các thiết bị bao hộ lao động. Do đó, các nhà máy tuyển cần phải có chương trình kỹ thuật kiểm soát và điều khiển chất lượng môi trường làm việc.

Trong các nhà máy tuyển, người lao động trực tiếp tiếp xúc với tiếng ồn là điều hiển nhiên. Vì vậy, để đảm bảo yêu cầu theo quy định về tiếng ồn tại nơi làm việc mức ồn cho phép tại các vị trí làm việc trong thời gian lao động ( $8 \mathrm{~h}$ - 1 ca sản xuất) không được vượt quá $85 \mathrm{dBA}$, mức cực đại không được vượt quá 115 dBA (Thông tư 24/2016/TT-BYT), đòi hỏi các nhà sản xuất phải có chương trình điều khiển và kiểm soát âm thanh một cách chặt chẽ.

Khi người lao động có nguy cơ phơi nhiễm tiếng ồn, cần phải cảnh báo để cách ly người lao động ra khỏi khu vực làm việc. Một phương án khác là các nhà sản xuất phải trang bị các thiết bị bảo vệ thính giác cho người lao động, tuy vậy phương án này cũng chưa chắc đảm bảo an toàn cho người lao động và thiết bị. Do vậy, trong tương lai các nhà máy tuyển khoáng cần nghiên cứu thiết kế các dây chuyền có tiếng ồn ở mức độ cho phép, cũng như giảm mức ồn của các thiết bị hiện có.

\subsection{Tăng năng suất và tỷ lệ thu hồi}

\subsubsection{Tăng năng suất}

Trong tương lai, quặng nguyên khai ngày càng nghèo đi. Trong khi yêu cầu về số lượng và chất lượng quặng tinh tiêu thụ ngày càng tăng. Vì vậy, áp lực tăng năng suất quặng nguyên khai và tăng thực thu quặng tinh đối với các nhà máy tuyển là rất lớn. Tuy nhiên, khi tăng năng suất tuyển, một số thiết bị trong nhà máy tuyển làm việc quá tải, làm giảm hiệu quả thu hồi của nhà máy, thậm chí còn gây rối loạn cho sơ đồ tuyển và làm tăng chi phí tuyển; tăng tỷ lệ mất mát các chất có ích vào đuôi thải; làm tăng lượng đuôi thải cần phải xử lý và tuổi thọ các bãi thải giảm,...

Nhà máy tuyển thuộc chi nhánh mỏ tuyển đồng Sin Quyền ở tỉnh Lào Cai có năng suất tuyển quặng nguyên khai khoảng 1,1 triệu tấn/năm, hàm lượng quặng nguyên khai trung bình 1,02\% Cu. Mỗi năm nhà máy sản xuất khoảng trên 41.700 tấn tinh quặng đồng, hàm lượng khoảng $25 \% \mathrm{Cu}$ với mức thực thu đồng trong tinh quặng khoảng $92,5 \%$. Nhưng do hàm lượng đồng nguyên khai đưa vào tuyển bắt đầu giảm so với thiết kế (chỉ còn $0,9 \div 0,95 \% \mathrm{Cu}$ ) và nhu cầu quặng tinh đồng cho quá trình luyện kim tăng cao, nên nhà máy đã tăng sản lượng lên trên 1,4 triệu tấn/năm. Để đảm bảo nhu cầu về tinh quặng đồng, nhà máy đã nghiên cứu cải tạo, thay thế hệ thống máy tuyển nổi nhằm tăng năng suất quặng nguyên khai (Lý Xuân Tuyên, 2018). Đồng thời lắp đặt thêm dây chuyền tuyển đồng 2. Do vậy, bãi thải quặng đuôi của nhà máy hiện nay đang tiềm tàng nhiều nguy hiểm.

Nhà máy tuyển quặng apatit Cam Đường ở tỉnh Lào Cai có công suất thiết kế 300.000 tấn quặng nguyên khai/năm, tương ứng với lượng bùn thải hàng năm khoảng 200.000 tấn. Nhưng thực tế trong nhiều năm qua, nhà máy đều làm việc với công suất vượt mức thiết kế từ $1,2 \div 1,5$ lần. Do vậy, sản phẩm đuôi thải hàng năm dao động $240.000 \div 300.000$ tấn. Hồ thải của nhà máy chỉ được thiết kế cho 10 năm chạy theo đúng công suất thiết kế, tuy nhiên đến nay nhà máy đã sản xuất được hơn 10 năm. Vì vậy, hồ thải của nhà máy trong những năm qua luôn nằm ở mức báo động, nguy hiểm và không an toàn. Để đảm bảo yêu cầu sản xuất, nhà máy đã nhiều lần phải đắp đập nâng chiều cao hồ thải và thường xuyên phải múc bùn và đổ thải vào các moong khai thác. Đây cũng chỉ là giải pháp tình thế vì hồ thải vẫn ở mức báo động, đồng thời chi phí vận chuyển bùn thải tốn kém.

Do đó, các nhà máy tuyển trong tương lai cần được thiết kế với năng suất cao hơn và phải có phương án tăng năng suất. Các nhà máy hoạt động với năng suất cao có ưu điểm: giá thành sản xuất rẻ, công nghệ hoàn thiện, hiệu suất tuyển cao, tạo được nhiều cơ hội việc làm hơn, xử lý môi trường tốt hơn,... Tuy nhiên, cũng sẽ cần phải có những bãi thải lớn hơn và do vậy, sẽ tiềm ẩn nguy cơ rủi ro cao hơn. Do đó, các nhà máy tuyển cần có phương án xử lý đuôi thải để sử dụng cho nhiều 
mục đích khác nhằm bảo vệ môi trường và giảm thể tích hồ thải.

\subsubsection{Tăng tỷ lệ thu hồi}

Khoáng sản là nguyên liệu không thể tái tạo, nên các nhà máy tuyển chịu áp lực rất lớn về yêu cầu tăng tỷ lệ thu hồi chất có ích, nhằm: bảo vệ khoáng sản; đảm bảo an ninh khoáng sản; giảm sản lượng khai thác nhưng vẫn đáp ứng được yêu cầu của hộ tiêu thụ; tăng tuổi thọ của mỏ; giảm tỷ lệ mất mát các chất có ích vào đuôi thải, đáp ứng các yêu cầu quy định của nhà nước.

Nhà máy tuyển đồng Sin Quyền, Lào Cai theo thiết kế có tỷ lệ thu hồi là 92,5 \%, Vào năm 2017, nhà máy đã tiến hành cải tạo hệ thống máy tuyển nổi nên tỷ lệ thu hồi đạt khoảng $94 \%$. Giả sử nhà máy có công suất là 1.000 .000 tấn/năm và hàm lượng đồng đầu vào $1 \% \mathrm{Cu}$, thì lượng đồng kim loại trong 1 năm là: $1.000 .000 * 1 \%=10.000$ tấn, nếu tỷ lệ thu hồi là $92,5 \%$ thì lượng đồng nguyên chất thu được sẽ là: $10000 * 92,5 \%=9.250$ tấn đồng/năm, tương tự khi tỷ lệ thu hồi là $94 \%$ thì sẽ thu được 9.400 tấn đồng/năm. Như vây, khi tỷ lệ thu hồi tăng đến $94 \%$ nhà máy đã thu hồi thêm được 150 tấn đồng kim loại/năm vào quặng tinh.

Hiện nay, tại Việt Nam vẫn còn nhiều nhà máy tuyển có tỷ lệ thu hồi thấp như các nhà máy tuyển quặng apatit có tỷ lệ thu hồi khoảng $70 \%$; cromit Cổ Định có tỷ lệ thu hồi khoảng $50 \%$,... dẫn đến chi phí sản xuất cao, hiệu quả tuyển thấp, tổn thất chất có ích vào đuôi thải lớn,...

\subsection{Quặng khó tuyển}

Trong những năm qua, sản lượng khai thác một số khoáng sản như: đồng; fenspat; apatit,... liên tục tăng, năm sau cao hơn năm trước. Biên giới khai thác mở rộng và ngày càng xuống sâu hơn. Quặng sau khai thác có thành phần vật chất phức tạp hơn; nghèo hơn và xâm nhiễm mịn hơn. Các dây chuyền và công nghệ tuyển trước đây đã không còn phù hợp với đối tượng quặng này.

Hiện nay, các nhà máy tuyển quặng apatit loại III tại Việt Nam đều được thiết kế để tuyển quặng apatit phong hóa với đất đá chủ yếu là thạch anh và một phần rất nhỏ là đôlômit. Công nghệ tuyển này đã được áp dụng 15 năm qua tại Việt Nam, nhưng hiện nay quặng nguyên khai cung cấp về nhà máy tuyển không ổn định về chất lượng, quặng ngày càng trở nên nghèo hơn, xâm nhiễm mịn hơn, thành phần vật chất phức tạp và nằm dưới đới phong hóa. Do đó, sơ đồ và chế độ công nghệ tuyển cũ không còn phù hợp, dẫn đến các chỉ tiêu công nghệ tuyển của các nhà máy thấp và không ổn định (Phạm Văn Luận, 2017).

Các nhà máy tuyển quặng sunfua: đồng, chì, kẽm, niken,... cũng gặp nhiều khó khăn do quặng ngày càng nghèo hơn, xâm nhiễm mịn và hàm lượng khoáng vật oxit tăng. Hiện tại nhà máy tuyển quặng niken Bản Phúc đã tạm dừng hoạt động do hàm lượng khoáng vật có ích quá thấp. Tương tự, các mỏ khai thác quặng chì - kẽm sunfua vùng Thái Nguyên và Bắc Kạn đã đến giai đoạn cuối. Nếu không có phương án tuyển và chế biến quặng chì - kẽm oxit hợp lý thì các mỏ này sẽ phải dừng hoạt động trong tương lai gần.

Vấn đề tuyển quặng cấp hạt mịn và siêu mịn cũng là một thách thức lớn đối với ngành tuyển khoáng. Khoáng vật có ích xâm nhiễm càng mịn thì chi phí nghiền càng tăng và hiệu quả thu hồi rất thấp. Ví dụ, mỏ cromit Cổ Định, Thanh Hóa có trữ lượng khoảng 25 triệu tấn $\mathrm{Cr}_{2} \mathrm{O}_{3} ; 3$ triệu tấn niken; khoảng 300 ngàn tấn coban và khoáng vật bentonit dưới hai dạng: quặng gốc và quặng sa khoáng (http://vampro.vn). Do giá trị kinh tế cao, loại quặng này đã được nhiều doanh nghiệp khai thác. Tuy nhiên, việc khai thác và tuyển hiện nay còn nhỏ lẻ, quy mô nhỏ, thô sơ, sơ đồ công nghệ tuyển đơn giản nên không tận thu được hết tài nguyên. Thành phần độ hạt, hàm lượng $\mathrm{Cr}_{2} \mathrm{O}_{3}$ và mức độ phân bố $\mathrm{Cr}_{2} \mathrm{O}_{3}$ theo từng cấp hạt của mỏ cromit Cổ Định như Bảng 2. (http://vampro.vn). Từ Bảng 2 nhận thấy: mỏ cromit Cổ Định chứa gần $70 \%$ cấp hạt $-0,045 \mathrm{~mm}$, hàm lượng $\mathrm{Cr}_{2} \mathrm{O}_{3}$ tập trung chủ yếu ở cấp hạt mịn $(0,02 \div 0,5 \mathrm{~mm})$. Các sơ đồ công nghệ tuyển đang được áp dụng tại mỏ chỉ có khả năng thu hồi quặng cỡ hạt thô (trền 0,1 $\mathrm{mm})$, còn cấp hạt mịn mất mát hầu hết vào đuôi thải, dẫn đến các chỉ tiêu công nghệ tuyển thấp, quặng tinh thu được từ các sơ đồ tuyển này có hàm lượng $31 \div 49 \% \mathrm{Cr}_{2} \mathrm{O}_{3}$ với mức thực thu $\mathrm{Cr}_{2} \mathrm{O}_{3}$ chỉ đạt xấp xỉ 50 \% (Lê Việt Hà, 2018). Do vậy, nhiệm vụ cấp bách nhất hiện nay tại mỏ là tìm kiếm phương pháp làm tăng hiệu quả thu hồi quặng cỡ hạt mịn.

Mặc dù, Việt Nam được đánh giá là nước có tiềm năng lớn về đất hiếm với trữ lượng 11 triệu tấn và được dự báo là 22 triệu tấn (Nguyễn Ngọc Anh, 1983). Nhưng đến nay, các mỏ đất hiếm lớn ở Việt Nam như Nậm Xe và Đông Pao vẫn chưa được khai thác công nghiệp. Do khoáng vật đất 
hiếm trong các mỏ này xâm nhiễm mịn và rất mịn. Theo kết quả nghiên phân tích thành phần độ hạt và mức độ phân bố oxit đất hiếm theo từng cấp hạt của tác giả Trần Thị Hiến (Bảng 3), thu hoạch cấp hạt -0,04 mm trong mỏ đất hiếm Bắc Nậm Xe lên đến 52,35 \% (Trần Thị Hiến, 2013). Vì vậy, hiện nay Việt Nam chưa xây dựng được công nghệ tuyển đất hiếm đảm bảo các chỉ tiêu kinh tế - kỹ thuật (Trần Văn Minh, 1984; Nguyễn Văn Hạnh, 1988, 2005; Naoto Yamagishi 2010; Trần Thị Hiến, 2013).

\subsection{Thu hồi tối đa các khoáng vật có ích}

Trong mỏ khoáng thường không chỉ có một khoáng vật có ích mà thường bao gồm nhiều khoáng vật có ích khác nhau, đôi khi những khoáng vật phụ lại có giá trị kinh tế cao hơn khoáng vật chính. Quặng đồng Sin Quyền - Lào Cai, ngoài khoáng vật chính chứa đồng là chancopirit $\left(\mathrm{CuFeS}_{2}\right)$ còn vàng, đất hiếm và manhetit,... Trong mỏ cromit Cổ Định - Thanh Hóa, ngoài khoáng vật chứa cromit còn có các khoáng vật bentonit, niken và coban. Các mỏ chì kẽm sunfua, ngoài chì, kẽm còn có bạc, indi,... Nhưng hiện nay, có rất ít các nhà máy tuyển quan tâm đến các sản phẩm phụ và chất thải có thể tận thu các khoáng vật có ích trong quá trình chế biến khoáng sản, gây lãng phí tài nguyên. Một số trường hợp, giá trị của chất thải rắn, lỏng bị loại bỏ khỏi dây chuyền chế biến quặng có giá trị kinh tế, chưa được tận dụng.

\subsection{Các yêu cầu về môi trường}

Luật bảo vệ môi trường ngày càng khắt khe hơn, yêu cầu các nhà máy tuyển phải thân thiện với môi trường. Trong tương lai sẽ có những nhà máy tuyển không có sản phẩm thải.

Vì vậy, các nhà máy tuyển cần nghiên cứu tái sử dụng sản phẩm đuôi thải; nghiên cứu trung hòa hoặc tách các hóa chất, ion độc hại trong quá trình tuyển như: các hydrocacbon, các ion kim loại nặng, axit, bazo,... để ngăn cản chúng xâm nhập vào mạch nước ngầm hoặc lan ra môi trường.

Bảng 2. Múc độ phân bố $\mathrm{Cr}_{2} \mathrm{O}_{3}$ theo tù̀ng cấp hạt của mỏ cromit Cổ Định.

\begin{tabular}{|c|c|c|c|c|}
\hline TT & Cấp hạt, mm & Thu hoạch, $\%$ & Hàm lượng Cr203, $\%$ & Thực thu Cr203, $\%$ \\
\hline 1 & $-10+5$ & 1,08 & 0,36 & 0,11 \\
\hline 2 & $-5+2$ & 2,88 & 0,91 & 0,75 \\
\hline 3 & $-2+1$ & 4,18 & 1,09 & 1,30 \\
\hline 4 & $-1+0,5$ & 3,31 & 1,81 & 1,72 \\
\hline 5 & $-0,5+0,25$ & 3,03 & 6,35 & 5,50 \\
\hline 6 & $-0,25+0,125$ & 7,20 & 13,24 & 27,33 \\
\hline 7 & $-0,125+0,074$ & 4,18 & 13,06 & 15,63 \\
\hline 8 & $-0,074+0,045$ & 4,83 & 11,24 & 15,54 \\
\hline 9 & $-0,045+0,020$ & 6,79 & 7,89 & 15,35 \\
\hline 10 & $-0,020+0,010$ & 8,95 & 1,63 & 1,18 \\
\hline 11 & $-0,010+0,00$ & 53,57 & 0,82 & 12,58 \\
\hline 12 & Cộng & 100,00 & 3,49 & 100,00 \\
\hline
\end{tabular}

Bảng 3. Mức độ phân bố oxit đất hiếm ở mỏ Bắc Nậm Xe.

\begin{tabular}{|c|c|c|c|c|}
\hline TT & Cấp hạt, $\mathrm{mm}$ & Thu hoạch, $\%$ & Hàm lượng $\mathrm{TR}_{2} \mathrm{O}_{3}, \%$ & Thực thu $\mathrm{TR}_{2} \mathrm{O}_{3}, \%$ \\
\hline 1 & $-10+5$ & 8,5 & 7,66 & 13,04 \\
\hline 2 & $-5+2$ & 8,24 & 7,72 & 12,73 \\
\hline 3 & $-2+1$ & 5,09 & 6,88 & 7,01 \\
\hline 4 & $-1+0,5$ & 3,39 & 6,18 & 4,2 \\
\hline 5 & $-0,5+0,25$ & 6,38 & 5,02 & 6,41 \\
\hline 6 & $-0,25+0,125$ & 5,12 & 4,66 & 4,78 \\
\hline 7 & $-0,125+0,071$ & 5,01 & 4,6 & 4,61 \\
\hline 8 & $-0,071+0,04$ & 5,91 & 4,38 & 5,18 \\
\hline 9 & $-0,04+0$ & 52,35 & 4,01 & 42,03 \\
\hline 10 & Cộng & 100 & 4,99 & 100 \\
\hline
\end{tabular}




\subsection{Tái chế phế thải rắn công nghiệp}

Ở Việt Nam, tốc độ tăng trưởng kinh tế và đô thị hóa nhanh chóng đã thúc đẩy nhiều ngành công nghiệp trong nước phát triển mạnh mẽ, kéo theo đó là một lượng lớn phế thải rắn phát sinh ngày càng lớn. Hiện tại, lượng chất thải rắn (CTR) sinh hoạt phát sinh ở Việt Nam khoảng 30 triệu tấn/năm với tốc độ gia tăng khoảng 10 \%/năm. Bên cạnh CTR sinh hoạt, nhiều loại CTR khác cũng đang gia tăng nhanh trong thời gian qua như CTR xây dựng, công nghiệp, y tế, nông nghiệp. CTR xây dựng được ước tính chiếm khoảng $25 \%$ khối lượng CTR tại Hà Nội, TP. Hồ Chí Minh và $12 \div 13$ \% tại các địa phương. Chỉ tính riêng Hà Nội, lượng CTR xây dựng phát sinh khoảng 2.000 tấn/ngày. CTR công nghiệp phát sinh chủ yếu từ các khu, cụm công nghiệp và đạt khoảng 8,1 triệu tấn vào năm 2016. Chất thải nguy hại công nghiệp thường chiếm $15 \div 20 \%$ lượng CTR công nghiệp, phát sinh chủ yếu ở các ngành công nghiệp nhẹ, luyện kim, hóa chất (https://isponre.gov.vn /home). Theo thống kê của chương trình môi trường Liên hợp quốc, mỗi người dân Việt Nam thải ra trung bình 1,3 kg chất thải điện tử năm 2018, tương đương 116.000 tấn. Theo báo cáo của Viện Khoa học và Công nghệ Môi trường (Trường Đại học Bách khoa Hà Nội), lượng phát thải tivi ở Việt Nam vào năm 2025 có thể lên tới 250.000 tấn. Lượng chất thải điện tử ở Việt Nam mỗi năm tăng khoảng 100.000 tấn, chủ yếu phát sinh từ hộ gia đình (https:// www.epa.gov/ sites/).

Nhu cầu trong nước đối với hầu hết các khoáng sản thô và tinh dự kiến sẽ còn tăng mạnh trong những năm tiếp theo của thế kỷ này. Do đó, việc kiểm soát và tái chế các phế thải rắn theo hướng thân thiện với môi trường là nền tảng để phát triển bền vững ngành công nghiệp khai khoáng và chế biến khoáng sản của Việt Nam.

\section{Kết luận}

Ngành công nghiệp tuyển và chế biến khoáng sản của Việt Nam trong thời gian qua chưa phát triển đúng với tiềm năng, vị trí và vai trò trong quá trình phát triển kinh tế - xã hội. Những hiện trạng và thách thức này cần phải được giải quyết ngay để đảm bảo cho ngành công nghiệp này phát triển bền vững và đáp ứng được các yêu cầu về an toàn và sức khỏe cho người lao động; đảm bảo chất lượng sản phẩm; thu hồi tối đa các thành phần có ích vào sản phẩm hàng hóa, chống lãng phí tài nguyên; giảm chi phí tuyển và thân thiện với môi trường,... góp phần phát triển kinh tế - xã hội, bảo vệ tài nguyên thiên nhiên và an ninh khoáng sản cho đất nước.

Do vậy, những người hoạt động trong lĩnh vực tuyển và chế biến khoáng sản cần tuyên truyền cho các đồng nghiệp, các nhà quản lý,... nhận thấy tầm quan trọng của khoáng sản đối với sự phát triển thịnh vượng kinh tế của đất nước. Trên cơ sở đó, cần sớm hoàn thiện hệ thống pháp luật, cơ chế điều hành và tăng cường kiểm tra, quản lý chặt chẽ về tài nguyên, thu hồi các mỏ hoạt động kém hiệu quả, đình chỉ các mỏ sử dụng công nghệ lạc hậu, đầu tư và phát triển công nghệ khai thác - chế biến khoáng sản và tái chế có chiều sâu, đồng thời không ngừng cải tiến, nghiên cứu và áp dụng công nghệ mới vào thực tế sản xuất, nhằm nâng cao hiệu quản lý và sử dụng tài nguyên khoáng sản của đất nước.

\section{Tài liệu tham khảo}

Http://vampro.vn/uploads/Tuyen\%20cromit\% 20Co\%20dinh.pdf

Https://www.epa.gov/sites/production/files/20 14-08/documents/vietnam_country_ presentation_2_prof_hai.pdf.

Http://consosukien.vn/ra-c-tha-i-die-n-tu-mo-ilo-nga-i-toa-n-ca-u.htm

Https://plo.vn/do-thi/moi-truong/tphcm-cansiet-chat-xu-ly-rac-thai-dien-tu-945794.htm

Lê Việt Hà, (2018). Nghiên cứu tuyểnquặng Cromit Cổ Định - Thanh Hóa cỡ hạt mịn bằng thiết bị tuyểnsiêu trọng lực Knelson và bàn đãi bùn. Đề tài cấp cơ sở, MS T18 - 03, Trường Đại học Mỏ - Địa chất.

Lý Xuân Tuyên, (2018). Kết quả nghiên cứu thay thế máy tuyển nổi cũ bằng máy tuyển nổi cơ giới - khí nén tự tràn tại nhà máy tuyển đồng Sin Quyền, Lào Cai. Hội inghị ERSD. Tr 258 - 264. Nhà xuất bản Giao thông Vận tải.

Naoto Yamagishi, (2010). Báo cáo nghiên cứu khả thi của thân quạng F3, Đông Pao, Lai Châu. Công ty Toyota Tsusho, Công ty Sojit.

Nguyễn Ngọc Anh, (1983). Báo cáo tìm kiếm thăm dò sơ bộ mỏ đất hiếm Bắc Nậm Xe. Đoàn 
địa chất 151, Lưu trũ địa chất U30.

Nguyễn Văn Hạnh, (1988). Nghiên cứu thí nghiệm bán công nghiệp công nghệ tuyển quặng đất hiếm Nam Nậm Xe. Viện Khoa học và Công nghệ Mỏ - Luyện kim.

Nguyễn Văn Hạnh, (2005). Nghiên cứu khả năng tuyển tách đất hiếm, fluorite và barite từ quặng hỗn hợp đất hiếm phong hóa Đông Pao. Luận án tiến sỹ. Trường Đại học Mỏ - Địa chất.

Phạm Văn Luận, (2017). Nghiên cứu tuyển nổi quặng apatit phối trộn vùng Bắc Nhạc Sơn - Lào Cai. Tạp chí Công nghiệp Mỏ, số 5 . tr13 - 16.
Số liệu tuyển sinh khoa Mỏ năm 2014 đến 2020, Trường Đại học Mỏ - Địa chất

Thông tư 24/2016/TT-BYT quy định về mức tiếp xúc cho phép với tiếng ồn.

Trần Thị Hiến, (2013). Thí nghiệm công nghệ quặng đất hiếm mỏ đất hiếm Nậm Xe. Viện Khoa học và Công nghệ Mỏ - Luyện kim.

Trần Văn Minh, (1984). Báo cáo tổng kết đề tài nghiên cứu công nghệ tuyển quặng đất hiếm Nam Nậm Xe quy mô phòng thí nghiệm. Viện Khoa học và Công nghệ Mỏ - Luyện kim. 